\title{
Research on China's Agricultural Low-Carbon Transforming Path
}

\author{
Zhixia Zhou ${ }^{1, \text { a }}$ \\ ${ }^{1}$ Department of Economy and Management, Weifang University, Weifang, China, 262100 \\ awfxyzhouzhixia@126.com
}

Keywords: Agricultural development, Lock-in constraints, Low-carbon transform

\begin{abstract}
In agricultural low-carbon transformation, China are encountering technique and regime lock-in constraints, the consequent triggered path-dependence and lock-in effects have inhibited technological innovation and institutional transformation in agriculture, thus seriously hindered transformation of modern agriculture. This thesis introduced the TIC structure model of "Technique-Regime Complex" into China's agricultural development, made the deep analysis of intrinsic, extrinsic and coupling motivation mechanisms from perspectives of technical and institutional economics, and designed the agricultural low-carbon transforming path based on evolutionary economics point. Based on practical investigation and research, we proposed that the implementation of induced agricultural technique vicissitude and mandatory agricultural regime vicissitude, were the pivotal paths to resolve agricultural technique and regime lock-in constraints. Our research has provided the scientific and applicable governing recommendations for agricultural low-carbon transformation.
\end{abstract}

\section{Introduction}

Currently, with the global warming being concerned, energy and environmental crisis aggravating increasingly, low carbon concept prevailing globally, low-carbon economy has become inevitable. Innovation and diffusion of low-carbon technique is the key to slow down global warming and to develop low-carbon economy, countries are committed to the R\&D and application of low-carbon technologies. A lot of facts and studies have shown that, technologies both reducing carbon emissions in economic activities and sharing low costs do exist (Anderson D, 2000; Harmelink M, 2003), however, application and diffusion of low-carbon technologies is relatively slow (Brown MA , 2008), the fundamental reason lies in the development of low-carbon economy has encountered the technique and regime lock-in.

In the stage of chemical agriculture and oil agriculture coming to the end, low-carbon agriculture is the sustainable development mode replacing oil agriculture. How to seize the opportunity and realize China's agricultural low-carbon transition as soon as possible according to the development trends of climate change and energy consumption, has become the new proposition urgently need to be resolved for China's modern agriculture development. However, the current agriculture transformation is encountering restrictive barriers from technique and regime lock-in, which has triggered the path-dependence and lock-in effects which are suppressing technique innovation and regime change in agriculture, and has hindered agricultural low-carbon alternative technologies and new governing regime from effectively implementing and diffusing, which has seriously obstructed transformation of modern agriculture.

Based on this, this thesis introduced TIC structure model of "Technique-Regime Complex" into Chinese agricultural development, tried to find the scientific and applicable governing recommendations and resolving paths for agricultural low-carbon transformation.

\section{Constraints on China's Agricultural Development}

The constraints of technique lock-in mainly reflect in: Firstly, the limitation of low-carbon agricultural technique cost. The high cost and high risk of agricultural technique adoption, and the weakness of agricultural technical supporting system, all of these has resulted in new technique can not 
be large-scale applied. Secondly, the leading effect of low-carbon agriculture to farmers' incomes is not strong. According to "brokers" principle of Adam Smith, the ultimate goal of farmers engaging in agricultural production is to maximize the economic benefits, currently low-carbon agriculture more emphasizes on agricultural energy conservation and farmers fails to get higher economic benefits, in the long-term game between economic interests and ecological interests, the economic interests tends to become the optimal choice. Thirdly, the lack of farmers' choosing power for low-carbon agricultural technique. The constraints of farmers' own cultural qualities, rural marginalization, and agricultural production patterns, as well as the dependence of technique adopters on traditional agricultural technique path, have made farmers miss choosing power for low-carbon agricultural technique. Due to the long-term path-dependence leading to technique lock-in, a number of effective low-carbon agricultural techniques have not been widely applied and promoted, which is restricting the process of agricultural low-carbon transformation.

The constraints of agricultural regime lock-in include both formal and informal regime, mainly reflect in: Firstly, lack of a sound agricultural policy system, such as agricultural regime arrangements, agricultural incentive policies and agricultural supportive system arrangements out of order, and other aspects. Secondly, lack of strong community promotion and efficient market-based instruments, such as imperfect government performance appraisal system, low sensitivity to market economy and insufficient low-carbon consumption demands of farmers, the high rely on collective economic organizations and government, and other aspects. Thirdly, restriction of traditional agricultural management system, based on traditional dispersed individual operators, farmers have uneven economic base and operation mode, the economic benefits of using alternative technologies are not obvious, which makes the low-carbon transformation take a long time to achieve. Constraints of regime lock-in has triggered high market transaction costs in agricultural development, stifled innovation of new agricultural management system, and made the inefficient high-carbon equalization system exist long-standing and difficult to change.

In the process of China's agricultural development, the above mentioned technical and regime restrictive elements nested within each other, strengthened interaction, and formed a giant and complicated carbon-based technical-economic-social system with path-dependent feature and containing large number of coupling elements and subsystems, which resulted in the co-evolution of technical system and governance system driven by scale returns increasing mechanism, made the current agricultural economy be locked in fossil and fuel based carbon-intensive energy system, and produced the sustained market failure and policy failure. In this "Technique - Regime Complex" (TIC) constituted by complex technical system and its embedding social environment, technique lock-in strengthened industrial lock-in, industry lock-in strengthened regime lock-in, regime and industry lock-in in turn strengthened technique lock-in, "Technique-Regime Complex" further strengthened path-dependence and lock-in effect in agricultural low-carbon transformation.

\section{Driving Mechanism of Agricultural Low-carbon Transition}

Agricultural low-carbon transformation development is a complex process, its dynamic factors include the internal driving force determined by market mechanism based on economic interests and the external driving factors determined by external environmental factors such as market, social, technique, policy and so on, and is the result of internal and external dynamic interaction.

As shown in Fig.1, under the constraints of technique and regime lock-in, Driving mechanism of China's agricultural low-carbon transformation is a comprehensive process, in which those bodies including resource companies and related industries, farmers, intermediaries, governments, universities and research institutes, under conditions of resource endowments, resource market and the external environment, coupling to each other and emerging as self-organizations with strong rooted nature. In agricultural transforming process, the key elements such as agricultural technique innovation and promotion, agricultural regime innovation and improvement are throughout the whole process of the industrial evolution. 


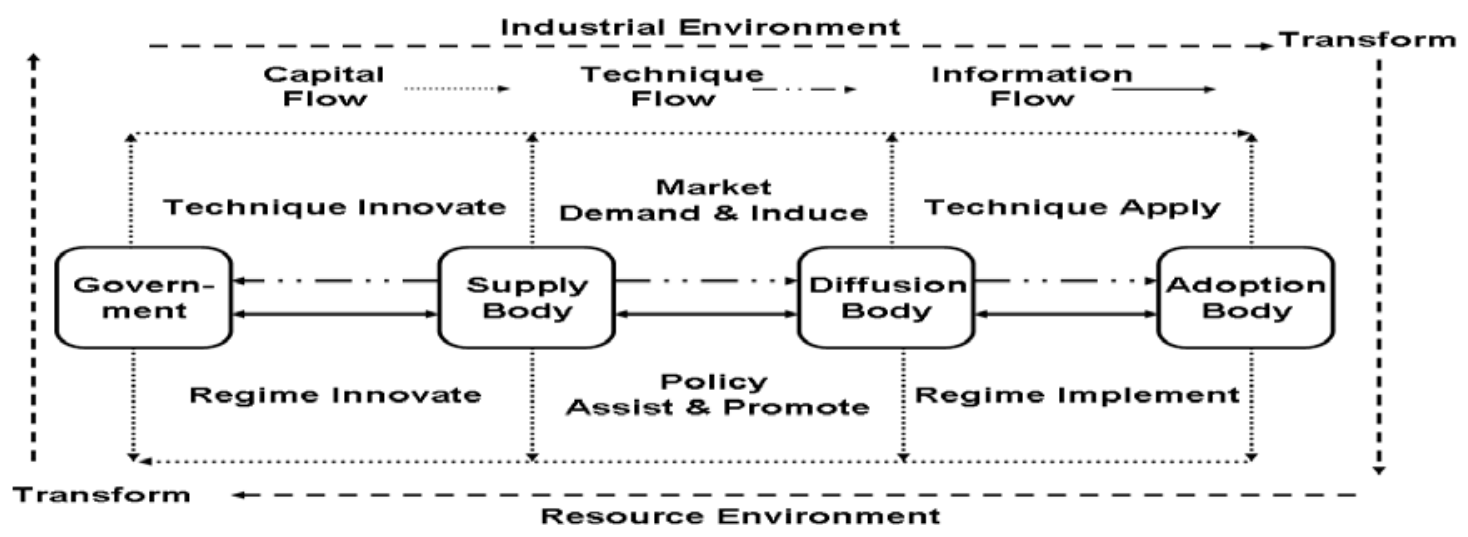

Figure 1. Driving mechanism of agricultural transition under constraints

The supply, adopting and diffusion of low-carbon agricultural technique is the pivotal path for agricultural transformation, in which the technique-supply bodies mainly include agribusiness organizations, research institutes and agricultural extension institutions, the technique-diffusion intermediary bodies include agricultural enterprises, cooperative organizations of farmers and agricultural training sessions and so on, the technique-adoption bodies mainly include the majority of farmers and some agribusinesses. Under the effects of internal driving mechanism induced by agricultural market demand interests, low-carbon agricultural technique is diffusing from the technique-supply bodies to technique-diffusion bodies, ultimately to technique-adoption bodies, which has promoted the transformation and development of traditional agriculture to low-carbon agriculture.

After the intrinsic motivation of agricultural industry restructuring, under the effects of extrinsic motivation mechanism driven by technique and regime innovation, the intrinsic motivation transforms into practical productive forces by switching role of industrial bodies, the agricultural economic benefits arising thereby are distributed among government, market and technique participating parties, which has triggered the industrial development and innovation activities, meanwhile industrial restructuring and development will also be counterproductive in market competing and consuming behaviors, thus will stimulate new momentum. Besides, the external environmental factors such as agricultural technique environment, industry environment, regime environment, natural resources and social environment are affecting each other, which also promote the agricultural low-carbon process.

Under the pull and influence of resource market and external environment, the inherent and extrinsic driving factors interact each other in agricultural transforming development, meanwhile supplemented by government policy and capital, coupling Driving mechanism of agricultural low-carbon transformation has been formed, thereby it promotes agriculture information, technique and capital to circulate in agricultural production and consumption fields, which has made agricultural low-carbon transformation exhibit a dynamic spiral evolution process with multi-forces interacting.

\section{Path Design of Agricultural Low-carbon Transition}

Based on the Driving mechanism analysis of agricultural low-carbon transformation under constraints of technique and regime lock-in, this thesis designs the developing path for agricultural low-carbon transformation under TIC theoretical framework, and will deeply explore evolutionary path in industrial transformation from the "Technique-Regime Complex" level. As shown in Figure 2 , through the implementation of agricultural technique and regime vicissitude paths, it has formed the technique support and regime guarantee for industrial transformation, thus has been contributing to agricultural low-carbon transformation. 


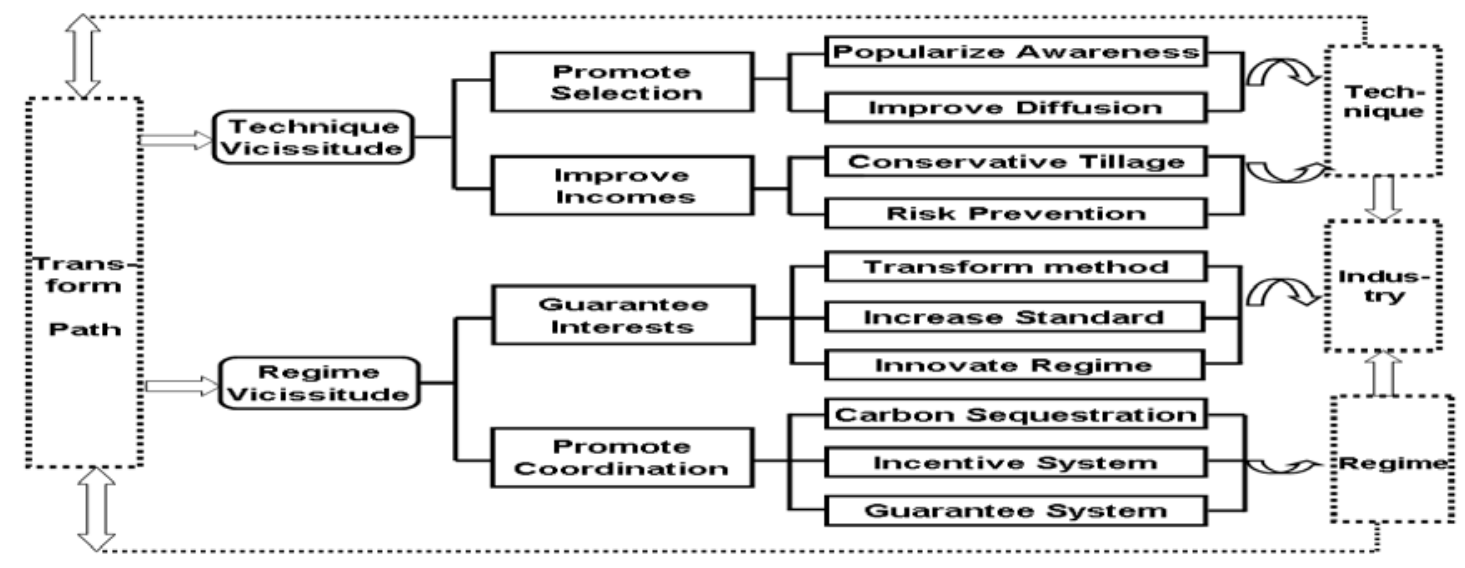

Figure 2. Achieving path for agricultural transformation under constraints

Considering the actual situation of China's agricultural development at present, the adoption and diffusion of low-carbon alternative technique need to use external effects, to introduce exogenous variables and implement induced technique vicissitude, thus can we achieve the torsion to original industrial development direction. By popularizing awareness of low-carbon technique and improving agricultural technique-extension system, local governments and agricultural technique extension institutions should try to increase farmers' awareness and acceptance of low-carbon agriculture. By encouraging farmers to adopt conservative tillage (such as reduction alternative, three-dimensional planting and breeding, waste recycling, etc.) and improving risk prevention system of low-carbon technique, governments should try to reduce the high cost and risk of alternative technologies, so as to achieve application and diffusion of low-carbon technique.

Reflecting from the perspective of technique and regime evolution path, the technique and regime lock-in constraints are only a temporary equilibrium state in evaluation process of technique and regime. Implementing compulsory regime vicissitude, is the main force to solve agricultural regime lock-in. Governments should encourage farmers to transform agricultural operating mode (for example, improve farmers' organizing degree and expand agricultural producing scale through farmer cooperative organizations), thus change the status quo of decentralized management; should encourage regime arrangements such as rural land transfer, thus effectively improve farmers' income and standard of living; should innovate agricultural resource property rights regime, so as to form low-carbon agricultural scale operating system, to guarantee and increase farmers' income in low-carbon production. Through promoting agricultural carbon sequestration and ecological compensation, completing agricultural incentive regime and improving agricultural guarantee system, local government should try to correct failures in agricultural regime and policy, improve market environment and social environment for agricultural low-carbon transformation, so as to achieve the balance of agricultural economic benefits and environmental ecological benefits.

\section{Conclusion}

Technique and regime lock-in caused the restrictive obstacles to China's agricultural development, inhibited the innovation of low-carbon agricultural technique and new agriculture system, resulted that low-carbon alternative technique and now governance system could not be effectively implemented and diffused, thus seriously hindered the process of agricultural low-carbon transformation. Based on TIC structure model of "Technique- Regime Complex" in technical and institutional economics, this study suggests that, the internal driving mechanism is induced by agricultural market demand interests, the external driving mechanism is dominated by technique and regime innovation, the coupling driving mechanism is interacted by internal market factors and external environment factors, all of these mechanisms interact and make the agricultural low-carbon transformation exhibit a dynamic spiral evolution process with multi-forces interacting.

Therefore, as to the reality constraints of China's agricultural transformation, implementing 
induced agricultural technique vicissitude and mandatory agricultural regime vicissitude from a technique-regime integrated level, is the pivotal path to resolve agricultural technique and regime constraints. Agricultural economic development itself is not likely to reduce agricultural carbon emissions through "environmental Kuznets curve" effect, so local governments and agencies at all levels should increase efforts on agricultural technique innovation and regime reform, accelerate transformation of agricultural operating system and producing methods, through technical advances to enhance resource using efficiency, and form the technique support and regime guarantee for agricultural industry transformation, so as to breakthrough the technique and regime constraints in production, and achieve agricultural low-carbon transforming development.

\section{Acknowledgment}

This thesis is founded by Shandong Province Human \& Social Science Program (17-ND-JJ-15), Shandong Province Soft Science Program(SD Simulation Research on Technical Innovation Promoting Shandong Agricultural Transformation), Shandong Province Natural Science Foundation Program (ZR2014GL010), National Spark Program (2013GA740012) and Shandong Spark Program (2012XH06033), hereby express acknowledgments to them.

\section{References}

[1] BI Jun. China's low-carbon town construction path in post-crisis era [J]. Nanjing Social Sciences, 2009, (11): 12-16.

[2] Li Zhiying, Li Hui. Study on landscape planning of contemporary urban agglomerations [J]. Collected Works of China Society of Landscape Architecture 2010, 291-292.

[3] WEI Hou-kai, ZHANG Yan. Thought and Measures to Promote the Green Transformation of Urbanization in China [J]. Economic Survey, 2011, (9): 15-17.

[4] LIU Shao-hua, XIA Yue-yao. Innovative development of low-carbon economy in the context of new urbanization [J]. Journal of Social Science of Hunan Normal University, 2012 (3): 84-87.

[5] Song Linfei.New urbanization of thinking [J]. Observation and thinking, 2014 (1): 19-22.

[6] Unruh, G.C. Unherstanding Carbon Lock-in [J]. Energy Policy, 2000, 28 (12): 817-820.

[7] Unruh, G.C. Globalizing Carbon Lock-in [J]. Energy Policy, 2006, 34 (10): 1185-1197.

[8] Unruh, G. C. Escaping Carbon Lock-in [J] .EnergyPolicy, 2002, 30 (4): 317-325.

[9] Zhuang Guiyang. Low-carbon economy climate change in the context of China's innovative development [M]. Beijing: Meteorological Press, 2007 (1): 55-59.

[10] Wang Yi. Innovative development of low-carbon economy to play a good time [N]. China Energy, 2009-8-20.

[11] Xie Laihui. Carbon Locking, Unlocking and Low-carbon Economy Road [J]. Price Monthly, 2009, (10): 8-14.

[12] Chen Xiaochun, Jiang Daoguo.The connotation and realization path of new urbanization low-carbon innovative development [J] Academic Forum, 2013 (4): 123-124. 